\title{
MEASUREMENT OF ORGANIZATIONAL EXCELLENCE IN INDIAN CONTEXT: AN EXPLORATORY STUDY
}

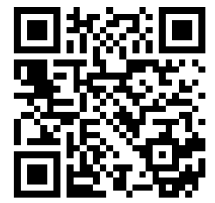

Sony kumari ${ }^{1}$, L. N. Bhagat ${ }^{*}$ 四

${ }^{1}$ Ph.D. Research Scholar, University Department of Commerce and Business Management, Ranchi University, Ranchi, India

${ }^{* 2}$ Professor of Economics (Retd.) \& Former President, Association of Indian, Management Schools (AIMS), India

DOI: https://doi.org/10.29121/ijetmr.v7.i12.2020.831

Article Citation: Sony kumari, and

L. N. Bhagat. (2020).

MEASUREMENT OF

ORGANIZATIONAL EXCELLENCE IN

INDIAN CONTEXT: AN

EXPLORATORY STUDY.

International Journal of Engineering

Technologies and Management

Research, 7(12), 25-32.

https://doi.org/10.29121/ijetmr.v7

.i12.2020.831

Published Date: 17 December 2020

Keywords:

Organizational Excellence

Measurement

India

Criteria

Public Sector

Organization

\section{ABSTRACT}

Organizational excellence is the most recognized organizational concept of the twenty first century. This study aims at exploring the criteria for measuring organizational excellence in the Indian context. The study is basically based on primary data collected from a sample of 50 executives using structured questionnaire. Judgment sampling technique is used for conducting the survey. The five point response category of Likert type has been employed to examine the responses of respondents. The percentage of respondents responded against each response category has been used to measure the extent of positive, neutral and negative responses. The data sorted out and Cronbach's alpha computed using Excel-07 and SPSS-20. The response analysis indicated that the organization under study has achieved satisfactory level of organizational excellence at the present time. The results are quite consistent to the saga of the organization. The study emphasizes the need for long-term strategy for achieving the goal of sustained excellence of the organization. Key contribution and limitations also indicated.

\section{INTRODUCTION}

The keyword, organizational excellence, conceptualized only in the twenty first century, represents one of the most recognized organizational concepts which provides confidence in the organization's ability to achieve longterm and sustained success in today's ever changing and global business environment through creating new approaches to their development. The pursuit of achieving organizational excellence can strengthen the overall prestige of an organization both internally and externally. Any additional costs to infrastructure and overhead have the potential to be rapid with greater returns resulting from engaged employees, satisfied customers and more efficient operations. Some findings from field research projects revealed a significant impact of organizational excellence on overall performance [1], human force productivity [2], company culture creating [3] and other such features of organizations.

The academic research and debate in the concept of organizational excellence dates back to Peters and Waterman in 1982 [4] but conceptualised only in the twenty first century. Continuous excellence evaluations have witnessed frequent changes in the definition of the term organizational excellence. Thawani [5] has evolved the six

(C) 2020 The Author(s). This is an open access article distributed under the terms of the Creative Commons Attribution License, which permits unrestricted use, distribution, and reproduction in any medium, provided the original author and source are credited. 
Measurement of Organizational Excellence in Indian Context: An Exploratory Study

- sigma strategy for organizational excellence. Six sigma links customer requirements and process improvements with financial results while simultaneously providing the desired speed, accuracy and ability in today's e-age. But six-sigma can be used in a highly focused and limited manner in specific areas of the business or in a wholesale strategic corporate initiative like General Electrical's (GE).

While conceptualizing the term organizational excellence Harrington [6] has viewed that organizational excellence is designed to permanently change the organization by focusing on managing the five key elements of the organization. Each of these five organizational elements is not new by itself. The key to Organizational Excellence is combining and managing them together. We call the methodology that provides a holistic approach to improving the organization's performance, 'Organizational Excellence', which is supported by five pillars that must be managed: Process Management, Project Management, Change Management, Knowledge Management, Resource Management. For this, we need to manage our process and continuously improve them for they are the way we obtain major improvements in our process and today, most organizations are doing a very poor job of project management as demonstrated by the high failure rate of projects. We need to manage the organization so that it is prepared for the chaos that it is being subjected to due to the magnitude and quantity of changes that must be implemented. We need to change the organization's knowledge that is the organization's most valuable asset. It is the organization's knowledge that gives an organization its competitive advantage. We need to manage our resources and assets for they drive our business results.

The word excellence has widely been used by many organizations to describe some aspect of their activities. Organizational excellence may be defined as the ongoing efforts to establish an internal framework of standards and processes intended to engage and motivate employees to deliver products and services that fulfill customer requirements within business expectations. It is the achievement by an organization of consistent superior performance for example, outputs that exceed meeting objectives, needs or expectations.

The European Foundation for Quality Management (EFQM) says that Excellent Organizations achieve and sustain superior levels of performance that meet or exceed the expectations of all their stakeholders. The EFQM has identified a number of 'Fundamental Concepts' that it has used to underpin its successful management framework, the EFQM Excellence Model. These are concepts that organizations aspiring to become excellent overall need to consider and put in place in ways relevant to them. The eight concepts are : Achieving balanced results, Adding value for customers, Loading with vision, Inspiration \& integrity, Managing by processes, Succeeding through people, Nurturing creativity \& innovation, Building partnerships, Taking responsibility for sustainable future. [7]

The most recent views on organizational excellence expressed by experts. For example, Webster [8] says that "Organizational excellence is delivering, and sustaining the delivery of outstanding value to all key stakeholders". Experts from American Society for Quality (ASQ) [9] argue that "Organizational excellence refers to on-going efforts to establish an internal framework of standards and processes intended to engage and motivate employees to deliver products and services that fulfill customer requirements within business expectations". Bailey [10] wrote: "The excellence is a cultural journey".

The organizational excellence models have been discussed and developed in more than 90 countries throughout the world. Ladzani [11] has made some interesting comparisons of different versions of excellence models. Nenadal et al. [12] have examined and listed the basic features of few selected excellence models, which are widely known and respected, taken from the group of models which are propounded by institutions and received national or internal awards and the group of models promoted by individuals, well known experts in the field.

Thus, the studies on organizational excellence clearly indicated that most of the researchers have taken up the cases of developed countries and built excellence models. But such studies are lacking very much in developing countries like India. The present study is an attempt in this direction and taken up the issue of measuring organization excellence in the case of Indian public sector organization namely Central Coalfields Limited (CCL) Ranchi, Jharkhand, one of the subsidiaries of Coal India Limited, the largest coal producing company in the world.

In view of the above, the objective of this study is to identify the criteria for measuring organizational excellence and examine the respondent's responses towards organizational excellence with respect to the identified criteria.

\section{THE DATA AND METHODOLOGY}

The study is basically based on the primary data collected from a sample of 50 respondents i.e. executives (out of 328 executives) using well structured questionnaire. The judgment sampling technique-one of the non-parametric 
Sony kumari, and L. N. Bhagat

sampling- was considered appropriate and used for conducting the survey. Judgment sampling is employed, when the participants are selected as per the researcher's convenience, confidence and experience that they will confirm to certain specific requirements, criteria/ parameters of the research [13].

The five point response category of Likert type [14] pertaining to respondent's responses has been employed with a view to examine the responses of respondents towards organizational excellence with respect to the criteria identified previously [15] for measuring organizational excellence.

The Likert type data has the benefit of solving the quandrum of measurement and qualification of behavioral and psychological traits. First the five point Likert responses are quantified by allocating numerical value 1 for Strongly Disagree (SD) and 5 for Strongly Agree (SA) with the questions. Then the criteria-wise analysis made on the basis of the percentage of respondents responded against the five point response category of Likert type. The data sorted out and Cronbach's alpha computed with the help of Excel-07 and SPSS-20.

\section{CRITERIA USED FOR MEASURING ORGANIZATIONAL EXCELLENCE}

The following criteria have been used for measuring the level of organizational excellence achieved so far by the organization.

Branding of Organization: Differential behavior is essential for organizational excellence. The brands make a difference. Even as the brains behind brands work hard at creating a brand identity that resonates strongly with end consumers, they are now challenged to come up with newer way to build a long term connect and brand stickiness. The best brands are exemplifying day in, day out, in the process generating a legion of fans that swear by them. In fact, brand is a set of parameters that gauged their innovativeness, stylishness, uniqueness, engagement, heritage and trustworthiness. Employee branding is intended to induce employee-brand in identification and a psychological connection between the employee and the brand. The strongest brands in the world own a place in the consumer's mind, and when they are mentioned almost everyone thinks of the same things.

Creating the Leaders of Tomorrow: The world has become more connected with increase in cross cultural transactions. Also, the technology is involving at a rapid pace. The workforce in India is becoming younger and participation of women in the workforce is also increasing. Today, leadership is much more about handling these complexities. The speed of decision making needs to be accelerated every day. It needs mind-set of learning, embracing change and adaptability. What is more important is creating leaders of tomorrow. What is required today is celebrating achievements of those playing a pivotal role in nurturing generation next. In fact, succession planning is vital for an organization's sustainability. The middle management should be groomed to tackle attrition as well as this group is arguably the most pressurized management group in the company. Leaders who can build culture and maintain culture coherence across a company's portfolio will create sustainable organizations of the future and clearly stand out. Hence, the journey to organizational excellence is an inside job. It begins with a paradigm shift for the leader, however, lasting success is contingent upon a majority of stakeholders learning to change their mind. Thus enabling them to actually see, think, feel, act, trust, and be in profoundly new ways [16].

Creating Environment for Growth and Business Excellence: It is truly important that the leaders should effectively blend the strategy and culture together to ensure growth of organizations. A tool called 'culture meter' may be considered as a growth driver. The culture meter is an online tool which will cumulatively tell us how we have to internalize values as an organization and how according to each leader, it is being driven. The second part of the tool's design would be to enable a multi stockholder view, after they feel and see the change and contribute to the same in the form of continuous feedback. The third part of the culture meter is involving the customer in the architecture and building process. This will lead to a fool-proof culture building process along with measurements and business excellence. This will, of course, be a robust future step framework which will drive the enterprise forward. Appropriate training and development programs may also help the company to create environment for growth and business excellence. Nenadal et al. have noted that organizational excellence must be seen as an excellent opportunity for long - term business success [12].

Adoption of Competency Based Recruitment \& Selection Process: For every organization it is important to have a right person on a right job. Recruitment and selection plays an important role in achieving organizational excellence. The term 'core competency' is believed to have been introduced in 1990 by the Harvard Business Review to describe a specialized expertise that can be leveraged as a competitive advantage. Competency - based human resource practices used competency framework (competencies that distinguish high performer from average 
performers in all areas of organizational activity) as a foundation for recruitment, selection, training and development. It forms the basis for all human resource functions and series as the linkage between individual performance and business result. It emphasizes the cognitive abilities (able to do) and forms a foundation of efficient well designed and effective recruitment and selection. 'These competencies will be the base for every human resource practices such as in selecting, recruiting, training, career developing, apprising performance and rewarding the employees. By doing this, organizations can ensure that competencies at the output level or in other words, performance is more measurable and easier to be obtained' [17]

Provision for Inclusive Growth: Inclusive growth has become a passion for all organizations searching for excellence. The concept of inclusive growth was first envisaged in India in the eleventh five year plan document which intended to achieve growth process with broad - based improvement in the quality of life and equality of opportunities to all. In the context of business organizations the Kayakalp model of Governance in used to achieve the goal of inclusive growth. It is based on transparency, ethics and philanthropy which are aimed at inclusive growth.

Green Technology for Sustainable Future: Environmental and eco - system restoration should be a conscious effort of any organization. The organization must be aware to the importance of environmental issues and should try to restore the environment and nature to its original pristine condition. Coal sector, in particular, takes it upon itself as a moral obligation. Green technology ensures the growth with human face and minimizing the risks in performing the activities by restoring eco - system.

Achieving Superior level of Performance: The European Foundation for Quality management (EFQM) says that "Excellent organizations achieve and sustain superior levels of performance that meet or exceed the expectations of all their stakeholders" [7].

Thus excellence is about sustained performance, it also follows that the organization should be planning to meet stakeholders' short and long term needs. Success is best achieved when organizations truly value their people and ensure their full involvement. People's potential is released when there is a culture of shared values, openness, trust and goals with those of their people. It is pertinent to note here that psychological safety makes the workplace more vibrant and innovative. It will have positive impact if and only if employees are allowed to question the leadership without fear of retaliation. In the absence of psychological safety where employees just do not feel assured enough to express themselves, they are reluctant to suggest ideas, share their anxieties or question leadership thinking. People should be able to lend their names to their questions without fear of retaliation. Admitting management slips and omissions is an act of vulnerability that can be role models for psychological safety. The top management must demonstrate this each time. And soon, the culture starts trickling down the guarantee of psychological safety must come right from the top.

\section{EMPIRICAL RESULTS AND DISCUSSION}

This section has two parts. First, presentation of descriptive statistics related to the reliability analysis. Second, presentation of the response analysis related to the respondent's responses towards organizational excellence with respect to the seven identified criteria used for measuring organizational excellence.

\subsection{RELIABILITY ANALYSIS}

This analysis in very important to check the assurance of the study for different respondents. The descriptive statistics along with Cronbach's alpha are presented in Table-1.

Table 1: Descriptive Statistics

\begin{tabular}{|c|c|c|c|}
\hline Scale & No. of Items & Sample size & Cronbach's alpha \\
\hline Organizational Excellence & 07 & 50 & 0.892 \\
\hline
\end{tabular}

Source: Computed form the survey data.

Table 1 revealed that the computed value of Cronbach's alpha (0.892) is more than the limit of reliability i.e. 0.70 [18]. This means that the organizational excellence scale is acceptable and it's reliability is ideal for further 
analysis. This result also indicated that all 7 criteria considered for measuring organizational excellence (as represented by the questions) are valid and suitable to measure the attitude of employee towards organizational excellence in the organization.

\subsection{RESPONSE ANALYSIS}

The response analysis conducted for each of the criteria considered for measuring organizational excellence as contained in different questions and for each of the five categories of response. The results are presented in Table2.

Table 2: Respondent's Responses

\begin{tabular}{|c|c|c|c|c|c|c|c|}
\hline \multirow[t]{2}{*}{ Questions } & \multicolumn{6}{|c|}{ Responses } & \multirow[t]{2}{*}{ Total } \\
\hline & & SD & $\mathrm{D}$ & $\mathrm{N}$ & A & SA & \\
\hline \multirow[t]{2}{*}{ Do you agree that CCL is branding for excellence? } & f & 10 & 23 & 11 & 06 & 00 & 50 \\
\hline & $\%$ & 20 & 46 & 22 & 12 & 00 & 100 \\
\hline \multirow[t]{2}{*}{ Do you agree that CCL is engaged in creating the leaders of tomorrow? } & $\mathrm{f}$ & 08 & 28 & 13 & 01 & 00 & 50 \\
\hline & $\%$ & 16 & 56 & 26 & 02 & 00 & 100 \\
\hline \multirow{2}{*}{$\begin{array}{l}\text { Do you agree that CCL creates environment for growth and business } \\
\text { excellence? }\end{array}$} & $\mathrm{f}$ & 07 & 31 & 12 & 00 & 00 & 50 \\
\hline & $\%$ & 14 & 62 & 24 & 00 & 00 & 100 \\
\hline \multirow{2}{*}{$\begin{array}{l}\text { Do you agree that competency based recruitment \& selection process is } \\
\text { adopted by CCL while appointing a person? }\end{array}$} & $\mathrm{f}$ & 07 & 30 & 10 & 03 & 00 & 50 \\
\hline & $\%$ & 14 & 60 & 20 & 06 & 00 & 100 \\
\hline \multirow{2}{*}{$\begin{array}{l}\text { Do you agree that recent campaign of CCL 'when sky is the limit the clouds } \\
\text { can't blur our vision' aims at inclusive growth? }\end{array}$} & $\mathrm{f}$ & 13 & 31 & 06 & 00 & 00 & 50 \\
\hline & $\%$ & 26 & 62 & 12 & 00 & 00 & 100 \\
\hline \multirow{2}{*}{$\begin{array}{l}\text { Do you agree that the community development activities under CSR are to } \\
\text { promote green technology for sustainable future? }\end{array}$} & $\mathrm{f}$ & 19 & 28 & 03 & 00 & 00 & 50 \\
\hline & $\%$ & 38 & 56 & 06 & 00 & 00 & 100 \\
\hline \multirow{2}{*}{$\begin{array}{l}\text { Do you agree that CCL is able to achieve superior level of performance that } \\
\text { meets or exceed the expectations of all their stakeholders? }\end{array}$} & $\mathrm{f}$ & 30 & 15 & 05 & 00 & 00 & 50 \\
\hline & $\%$ & 60 & 30 & 10 & 00 & 00 & 100 \\
\hline
\end{tabular}

Source: Computed from the survey data.

Branding for Excellence: The results presented in Table 2 (Sl. No. 1) revealed that Sixty Six percent respondents have either agreed (46\%) or strongly agreed (20\%) with the question "Do you agree that CCL is branding for excellence?" Rest thirty four percent have expressed their indifferent attitude (22\%) or disagreed $(12 \%)$. This may be taken to indicate that CCL is doing well with branding of the organization.

Creating the Leaders of Tomorrow: The results presented in Table 2 (Sl. No. 2) indicated that seventy two percent of respondents have either agreed (56\%) or strongly agreed (16\%) with the question "Do you agree that CCL is engaged in creating the leaders of tomorrow?". Only twenty eight percent respondents have either become neutral $(26 \%)$ or disagreed (2\%). This might indicate that the senior executives, very honestly, mentor and guide the junior executives with a view to create the leaders of tomorrow.

Creating Environment for Growth and Business Excellence: The results presented in Table 2 (Sl. No. 3) shows that seventy six percent respondents have either agreed (62\%) or strongly agreed (14\%) that CCL created environment for growth and business excellence by organizing appropriate training and development programs for the employees (executives in this case). Rest twenty four percent have expressed their indifferent attitude by expressing themselves as neutral. This might indicate that CCL creates environment for growth and business excellence by organizing appropriate training and development programs.

Adoption of Competency Based Requitment and Selection Process : Result in Table 2 ( Sl. No. 4) reveled that seventy four percent respondents have either agreed (60\%) or strongly agreed (14\%) that competency based recruitment and selection process is adopted by CCL while appointing a person. Only twenty six percent of respondents have either become neutral (20\%) or disagreed (6\%). This might indicate that CCL is taking all measures for getting good persons in the company; may be owing to the use of competency based recruitment and selection process, while appointing. 
Provision of Inclusive Growth: Results presented in Table 2 (Sl. No. 5) indicated that eighty eight percent respondents either agreed (62\%) or strongly agreed (26\%) that recent campaign of CCL 'when sky is the limit the clouds cannot blur our vision' aims at inclusive growth. Only twelve percent respondents have shown their indifferent attitude by expressing their views as 'neutral'. This may be taken to indicate that CCL is very successfully achieving the goal of inclusive growth and moving towards excellency.

Green Technology for Sustainable Future: Results in Table 2 (Sl. No. 6) revealed that ninety four percent of respondents have either agreed (56\%) or strongly agreed (38\%) that the community development activities under CSR is to promote green technology for sustainable future. Only six percent of respondents have preferred to choose their answer as neutral in reply to their question. Very high positive response of sample respondents might indicate the seriousness of CCL about sustainable future and doing great many things to preserve the natural resources for their use by future generation.

Achieving Superior level of Performance: Results presented in Table 2 (Sl. No. 7) showed that ninety percent of respondents have either agreed (30\%) or strongly agreed (60\%) that CCL is able to achieve superior level of performance that meets or exceed the expectations of all their stakeholders. Only quite a few (10\%) have shown their indifferent attitudes. This may be taken to indicate that CCL is able to achieve superior level of performance that meets or exceed the expectations of all their stakeholders and fulfils the criterion of organizational excellence.

Thus, keeping in view of the responses of respondents with respect to various criteria of organizational excellence it is quite clear that CCL has achieved the comfortable status (if not targeted) of organizational excellence. These responses are quite consistent with the saga of CCL. The CCL added a chapter of extraordinary success in the glorious history of the company during the financial year 2007-08. It has achieved a record production of 44.15 million tones, the highest ever in the history, despite several constraints. Again, CCL has achieved the ambitious target of 67 million tones during the financial year 2015-16. The company has made a spectacular turn-around, a couple of years back and has gone from step to step by registering record production, productivity, profit and people's care i.e. 4Ps. CCL is awarded with the prestigious 'HR Orientation Award' on February 15, 2017 for outstanding contribution in the field of human resources. The company has also bagged the 'National Safety Award (mines)' in New Delhi on December 16,2019 in recognition of its Lowest Injury Frequency Rate (LIFR) per million cubic meter output in 2016 at Jarangdih open cast project in Kathara command area [15, p. 41]. Very recently CCL recorded its highest - ever daily production of 6 lakh tones of coal on march 28,2020 to ensure unhindered power supply amid the COVID-19 Pandemic; CCL supplies 80\% of its mined coal to power plants of 10 states in India [19].

Response analysis has enabled us to offer an alternative definition of the keyword. "Organizational excellence is a particular stage in the process of continuous improvement which an organization achieves by doing well with branding, creating future leaders \& environment for growth \& business excellence using competency based recruitment \& selection process, techniques of inclusive growth \& sustainable future and consequently able to achieve superior level of performance that meets the expectation of all stockholders."

\section{CONCLUSION}

An attempt has been made in this study to measure organizational excellence in the Indian context through validating the sale of organizational excellence based on five point response category of Likert type and examining the responses towards organizational excellence with respect to identified criteria. The reliability result showed that the organizational excellence scale is acceptable and reliable. The response analysis clearly indicated that CCL has achieved satisfactory level of organizational excellence at the present time. This is born out by the facts, revealed by respondent's responses, that CCL is doing well with branding of organization, creating the future leaders, creating environment for growth and business excellence using competency based recruitment and selection process, promoting green technology for sustainable future and able to achieve superior level of performance that meets the expectation of their stakeholders. This study may be of great help in formulating ambitious long- term strategy for achieving the goal of sustained excellence of the organization. 


\section{KEY CONTRIBUTION AND LIMITATIONS}

This study is an attempt to validate the Likert scale in measuring organizational excellence in the Indian context and thus extends the knowledge on organizational excellence in the field of organizational studies. The alternative definition offered for the term 'organizational excellence' may also be considered as a noble attempt in this direction.

This study is based on a sample of only 50 respondents i.e. executives. Greater sample size could have provided more reliable results. The methodology used in measuring organizational excellence is the respondent's responses towards organizational excellence, which is subject to respondent's bias. The Likert scores used in response analysis are a direct measure of fairness, wherein the respondents might have experienced a confirmatory bias in attempting seven questions considered in the questionnaire. Further there is much scope to improve the alternative definition offered; the future researchers may provide more robust definition applicable to India. The excellence model applicable to India may also be explored.

\section{SOURCES OF FUNDING}

This research received no specific grant from any funding agency in the public, commercial, or not-for-profit sectors.

\section{CONFLICT OF INTEREST}

The author have declared that no competing interests exist.

\section{ACKNOWLEDGMENT}

This article forms a party of Ph.D. thesis completed by Sony Kumari [15] under the supervision of Dr. M.C. Mehta, Associate Professor, University Department of Commerce and Business Management, Ranchi University Ranchi. The authors, particularly the first author, acknowledges the receipt of academic assistance and guidance throughout the preparation of this article

\section{REFERENCES}

[1] Musa, P. and Tulay, G., Investigating the impact of organizational excellence and leadership on achieving business performance: An exploratory study of Turkish firms, SAM Advance Management Journal, 73 (1), 2008, 29-45.

[2] Shirvani, A. and Iranban, S., Organizational excellence performance and human force productivity promotion: A case study of South Zagros Oil and Gas production company, Iran, European Online Journal of Natural and Social Sciences, 2(3), 2013, 3010-3015.

[3] Zgodavova, K., Hudec, O, and Palfy, P., Culture and Quality: Insight into foreign organizations in Slovakia, Total Quality Management \& Business Excellence (e-Journal), 28, (9-10), 2017, 1054-1075, (DOI: 10.1080/14783363.2017.1309120).

[4] Peters, T.J. and Waterman, R. H., In search of Excellence: Lessons from America's Best Run Companies, (First Edition), Harper \& Row, New York, USA, 1982, p. 360.

[5] Thawani, Sunil, Six Sigma-Strategy for Organizational Excellence, The Total Quality Management \& Business Excellence, 15(5-6), 2004, 655-664. Available at http://dx.doi.org/10.1080/14783360410001680143 (Accessed on June 17, 2016).

[6] Harrington, H.J., The Five Pillars of Organizational Excellence, paper presented at 9th International Convention on Quality Improvement, November 14-15, 2005, Karanchi, Pakistan, p.5.

[7] Methurst, D. and Richards, D., The Fundamental Concepts of Organizational Excellence: A Blueprint of Success, D \& D Excellence Limited, 2006-2010, Available at http://www.ddexcellence.com (Accessed on May 20,2016).

[8] Webster, M., Organizational Excellence, so what is Organizational Excellence 2016, Available at https://realorganizationalexcellence.com/2011/08/25/so-what-is-organizational-excellence (Accessed on December 29, 2019).

International Journal of Engineering Technologies and Management Research 
[9] ASQ, What is Organizational Excellence? (Online) 2015, Available at http://asq.org/learn-aboutquality/organizational-excellence(Accessed on December 29,2019).

[10] Bailey, D.M., Journey to Excellence, Quality Progress, August 2014, pp. 42-45.

[11] Ladzani, W., Benchmarking the South African Excellence Model against World Class best practice business excellence models, Environmental Economics (e-journal) 7(4), 2016, 8-19.

[12] Nenadal, J. Vykydal, D.and Ealoszek, D., Organizational Excellence: Approaches, Models and their use at Czeck Organizations, Quality Innovation Prosperity, 22 (2), 2018, 47-64.

[13] Hair, J.F., Bush, R.P. and Ortinau, D.J., Marketing Research: Within a changing information environment, (Second Edition) 2003, Mc Graw- Hill, New York.

[14] Likert, R., A Technique for the Measurement of Attitudes, 1932, The Science Press, New York, Also Archives of Psychology, 22 (40), 1-55.

[15] Kumari, Sony, Motivation and Employee Satisfaction for achieving Organizational Excellence: A Case study of Central Coalfields Limited, Ranchi, Ph.D. Thesis submitted to Ranchi University, Ranchi, 2020.

[16] Shelton, C.D., Darling, J.R. and Walker, E.W., Foundations of Organizational Excellence: Leadership Values, Strategies and Skills, LTA, 1 (2), 2002, p.48.

[17] Kumar, Manish, A Study of competency-based recruitment and selection process at CCL, Ranchi, Jharkhand, ARISOM Journal of Social Sciences, 1 (2), 2019, p. 25 (ISSN: 2581-6365-P).

[18] Nunnally, J.C., Psychometric Theory, (Second Edition) 1978, Mc Graw- Hill, New York.

[19] The Times of India, Amid Lockdown, CCL records its highest daily production, Ranchi Edition, Times City, March 30, 2020, p. 3. 